\title{
Dietary nicotinic acid supplementation improves hepatic zinc uptake and offers hepatoprotection against oxidative damage
}

\author{
Rashmi S. Tupe ${ }^{1,2}$, Santosh G. Tupe ${ }^{1}$ and Vaishali V. Agte ${ }^{1 *}$ \\ ${ }^{1}$ Agharkar Research Institute, G. G. Agarkar Road, Pune 411 004, India \\ ${ }^{2}$ Rajiv Gandhi Institute of Information Technology and Biotechnology, Bharati Vidyapeeth University, Katraj, Pune 411 043, \\ India
}

(Received 4 June 2010 - Revised 19 October 2010 - Accepted 1 December 2010 - First published online 25 January 2011)

\section{Abstract}

We examined the effect of dietary nicotinic acid (NA) variations before and after oxidative stress (OS) treatment on the antioxidant defence system, function and morphology of the liver along with Zn status in rats. OS was generated by three intraperitoneal injections of tert-butyl hydroperoxide in the first week for the pre-exposure group and in the third week for the post-exposure group, respectively. These groups were further divided into subgroups and fed on a diet with marginally deficient $\mathrm{Zn}(10 \mathrm{mg} \mathrm{Zn} / \mathrm{kg}$ diet $)$ and NA variations as NA deficient, normal and excess with 10,30 and $1000 \mathrm{mg} \mathrm{NA} / \mathrm{kg}$ diet, respectively. Aspartate aminotransferase and alanine aminotransferase levels were elevated in rats with OS coupled with the Zn- and NA-deficient diet, which decreased towards normal with excess dietary NA. Excess NA supplementation in the OS pre-exposure group resulted in nearly preserved hepatic architecture with normal hepatocytes, whereas maximum tissue destruction was evident in the post-exposure group with NA deficiency. Dose-dependent improvement in the antioxidant defence system, enhanced reduced glutathione levels, lowered lipid peroxidation and higher hepatic Zn levels were observed with NA supplementation. The effect was more prominent in the pre-exposure group. In conclusion, dietary NA supplementation improves hepatic $\mathrm{Zn}$ uptake and results in hepatoprotection against OS-induced damage in rats.

Key words: Nicotinic acid supplementation: Oxidative stress: Antioxidants: Zinc deficiency

Antioxidants are substances that counteract free radicals and prevent the damage caused by them. In recent years, antioxidants have emerged as promising prophylactic and therapeutic agents ${ }^{(1)}$. Nicotinic acid (NA), also known as niacin (vitamin $\mathrm{B}_{3}$ ), is considered as a major antioxidant since it influences multiple pathways tied to both cellular survival and cellular death. During oxidative stress (OS), NA protects the cell by blocking cellular inflammatory cell activation, early apoptotic phosphatidylserine exposure and late nuclear DNA degradation ${ }^{(2)}$. NA supplementation has been shown to reverse OS-induced cell injury in kidney epithelial HEK 293 cells ${ }^{(3)} \cdot \mathrm{Zn}^{2+}$ is another major antioxidant that offers protection through the antagonism of redox-active transition metals, such as $\mathrm{Cu}$ and $\mathrm{Fe}$, the induction of metallothionein synthesis, the guarding of protein sulfhydryl groups from oxidative damage ${ }^{(4,5)}$ and the stabilisation of $\mathrm{Cu}-\mathrm{Zn}$ superoxide dismutase $(\mathrm{SOD})^{(6)}$. $\mathrm{Zn}$ is necessary for normal liver function, as $\mathrm{Zn}$ deficiency could participate in the pathogenesis of liver diseases $^{(7)}$ and reduced hepatic $\mathrm{Zn}$ levels have been correlated with impaired liver function and regeneration ${ }^{(8)}$. It has also been reported that $\mathrm{Zn}$ deficiency leads to a rapid increase in cellular oxidants ${ }^{(9,10)}$.

Vitamins such as riboflavin, NA, thiamin, folic acid and ascorbic acid have functional groups reported to be capable of forming complexes with $\mathrm{Zn}$. Our previous studies with erythrocytes $^{(11)}$, Caco-2 cells ${ }^{(12)}$ and hepatocytes ${ }^{(13)}$ have demonstrated the effects of NA, folic acid and ascorbic acid on $\mathrm{Zn}$ bioavailability, indicating interactions between vitamins and $\mathrm{Zn}$. The results from in vitro experiments demonstrated that improved $\mathrm{Zn}$ metabolism can be achieved through enhanced $\mathrm{Zn}$ absorption (intestinal) and post-absorptive uptake (hepatic) especially under OS conditions in the presence of NA. Another study from our laboratory has revealed that NA supplementation as a finger millet-based diet resulted in a significant enhancement of $\mathrm{Zn}$ absorption, hepatic $\mathrm{Zn}$ levels and growth of weanling mice ${ }^{(14)}$. In a recent study, we have reported a dose-dependent increase in hepatic NA accumulation as dietary $\mathrm{Zn}$ levels increased from deficient to excess $^{(15)}$. The interaction between $\mathrm{Zn}$ and NA seems to be bidirectional. Therefore, it was thought worthwhile to explore

Abbreviations: ALT, alanine aminotransferase; AST, aspartate aminotransferase; GI, group I; GII, group II; GIII, group III; GPx, glutathione peroxidase; GSH, glutathione; i.p., intraperitoneal; NA, nicotinic acid; OS, oxidative stress; SOD, superoxide dismutase.

*Corresponding author: V. V. Agte, fax +912025651542, email vaishaliagte@hotmail.com 
the efficacy of NA administration in attenuating the adverse effects caused by OS exposure to a $\mathrm{Zn}$-deficient state in vivo. Hence, animal experiments were conducted wherein the effect of NA on $\mathrm{Zn}$ metabolism under $\mathrm{Zn}$ deficiency and OS in growing rats was investigated, and the findings are reported in the present study.

\section{Experimental methods}

\section{Animals, diet and experimental design}

Weanling male Wistar rats weighing 50 (SD 10) g were procured from the animal facility, Agharkar Research Institute, Pune. The animal experiments' protocol was approved by the Agharkar Research Institute's Institutional Animal Ethics Committee, and the rats were treated according to the guidelines set by the Committee for the Purpose of Control and Supervision of Experiments on Animals.

The animals were housed individually in polypropylene cages in the institute's animal house under hygienic conditions in a room maintained at $24 \pm 2^{\circ} \mathrm{C}$ and with a $12 \mathrm{~h}$ light $-12 \mathrm{~h}$ dark cycle. During the study period of 3 weeks, the rats were fed with a modified AIN-93G diet prepared according to the American Institute of Nutrition guidelines ${ }^{(16)}$, containing casein as the source of protein, wheat bran as the source of fibre, and maize starch and sucrose as the sources of carbohydrates. All rats were fed the treatment diets and distilled water ad libitum, throughout the experimental period. A weekly record of body-weight changes and food intake of rats for all groups was maintained. The only variations were that $\mathrm{Zn}$ content in the diet (added as $\mathrm{ZnSO}_{4}$ ) was at a marginally deficient level (10 mg Zn/kg diet), and NA was given at three levels, namely deficient (10 $\mathrm{mg} \mathrm{NA} / \mathrm{kg} \mathrm{diet}$ ), adequate (30 mg NA/kg diet) and excess (1000 mg NA/kg diet). The reported excess dietary NA supplementations were from 500 and $1000 \mathrm{mg} / \mathrm{kg} \mathrm{diet}{ }^{(17)}$ to pharmacologically supplemented $4 \mathrm{~g} \mathrm{NA} / \mathrm{kg} \operatorname{diet}^{(18)}$.

The study design and grouping of animals for the experiment are shown in Fig. 1. Group I (GI, $n$ 8) animals served as normal controls and were fed with an AIN-93G diet containing adequate $\mathrm{Zn}$ and NA (30 mg each/ $\mathrm{kg}$ diet). The remaining animals were randomly divided into two main groups, groups II and III (GII and GIII), which were with OS and without OS, respectively. NA supplementation may improve $\mathrm{Zn}$ metabolism and prevent or cure OS-induced damage, hence it was decided to assess this by inducing OS before and after the dietary NA addition, respectively. Considering these variables, the main group GII was subdivided into two sets depending on the OS treatment (intraperitoneal (i.p.) injections of tert-butyl hydroperoxide) within the experimental period of 3 weeks, which were (1) pre-exposure (OS treatment in the first week only) and (2) post-exposure (OS treatment in the third week). At each OS exposure condition, dietary NA levels varied as deficient, normal and excess states, which resulted in a total of six treatment subgroups ( $n$ 8), i.e. GIIa, GIIb and GIIc for preexposure and GIId, GIIe and GIIf for post-exposure. The corresponding six control groups (GIIIa-GIIIf) were also maintained, wherein only NA variation was done without any OS treatment (i.p. injections of saline). For pre-exposure, GIIa, GIIb and GIIc animals were given OS treatment by i.p. injections of $0.22 \mathrm{mmol} / \mathrm{kg}$ body weight of tert-butyl hydroperoxide on the 2nd, 4th and 6th day of the first week. The respective controls GIIIa, GIIIb and GIIIc were given i.p. injections of saline on the same days. All these groups were given a normal American Institute of Nutrition diet (containing $30 \mathrm{mg}$ $\mathrm{Zn}$ and NA each/kg diet) during the first week, whereas for the next 2 weeks, the groups were maintained on a specific diet assigned to each group (marginally deficient $\mathrm{Zn}$ with respective NA levels - deficient, normal and excess). For post-exposure, animals were maintained on a specified diet for the first 2 weeks, and a normal diet and the treatment of three i.p. injections (one every alternate day) of tert-butyl hydroperoxide (for GIId, GIIe and GIIf) or saline (for GIIId, GIIIe and GIIIf) were given in the third week. The diet and OS treatment schedule for GII and GIII animals is shown in

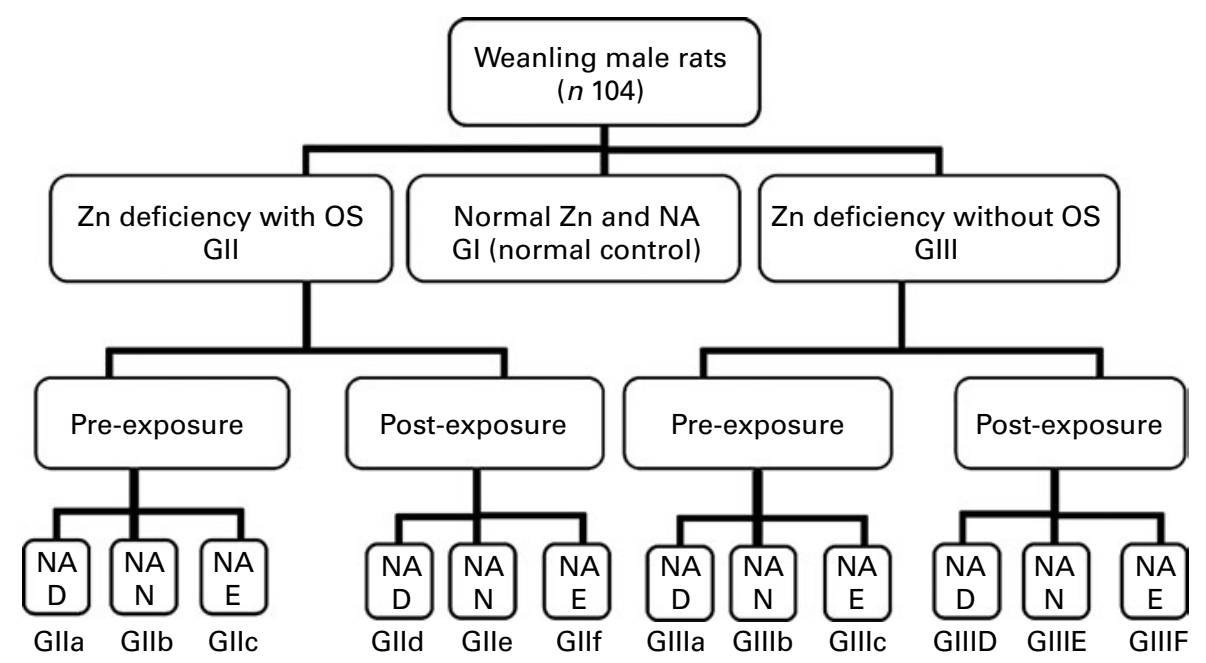

Fig. 1. Design of an in vivo animal experiment for studying the effect of nicotinic acid (NA) supplementation on zinc metabolism under different oxidative stress (OS) exposure conditions. NA D, NA deficient; NA N, NA normal; NA E, NA excess; GI, group I; GII, group II; GIII, group III. 
(a)

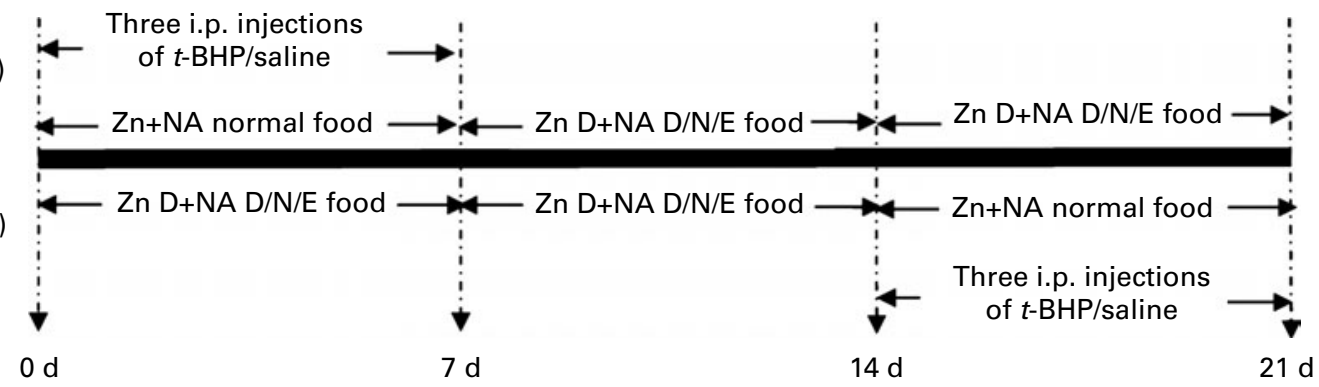

Fig. 2. Oxidative stress (OS) and diet schedule for groups II and III animals during the (a) pre-exposure and (b) post-exposure OS treatment. i.p., Intraperitoneal; $t$-BHP, tert-butyl hydroperoxide; NA D, nicotinic acid deficient; NA N, NA normal; NA E, NA excess; ZnD, zinc deficient.

Fig. 2. The design was thought to help in better understanding the role of NA supplementation in $\mathrm{Zn}$ metabolism and OS.

\section{Tissue sampling}

After 3 weeks, the rats were deprived of food for $6 \mathrm{~h}$ and then euthanised under light diethyl ether anaesthesia. Blood was collected by cardiac puncture into EDTA-containing tubes. After collecting the blood, the animals were dissected, and the livers were excised and rinsed in PBS. A small section of each liver was placed in $10 \%$ phosphate-buffered formalin for histopathological analysis, and the remaining liver tissue was processed for various biochemical estimations. The blood samples were centrifuged at $4000 \mathrm{rpm}$ for $10 \mathrm{~min}$. The plasma was separated and processed on the same day for the estimation of liver marker enzymes, such as aspartate aminotransferase (AST) and alanine aminotransferase (ALT).

\section{Estimation of liver marker enzymes in plasma}

The enzyme activities of AST and ALT were estimated using commercial kits (Ranbaxy Diagnostics Ltd, Baddi, H.P., India) as described previously ${ }^{(15)}$, and the enzyme activities are expressed in terms of IU/1 of plasma at $37^{\circ} \mathrm{C}$.

\section{Histopathological studies}

For histopathology, liver samples fixed in formalin were dehydrated in ascending grades of alcohol, cleared in benzene and embedded in paraffin wax. The blocks were cut into 5-7 $\mu \mathrm{m}$ thin sections, which were then double-stained with haematoxylin and eosin. After staining, the sections were observed under a light microscope and photographed.

\section{Biochemical analysis}

The liver samples were homogenised in $100 \mathrm{~mm}$-potassium phosphate buffer ( $\mathrm{pH} 7 \cdot 5$ ) containing $0 \cdot 15 \mathrm{M}-\mathrm{KCl}$ with a Potter-Elvehjem homogeniser to obtain $10 \%$ homogenate. Tissue homogenates were centrifuged at $10000 \mathrm{~g}$ for $30 \mathrm{~min}$ at $4^{\circ} \mathrm{C}$, and the supernatants were used for the estimation of different enzymes, protein, reduced glutathione (GSH) and lipid peroxidation.
Catalase, SOD and glutathione peroxidase (GPx) activities were determined by following the methods of Clairborne \& Fridovich $^{(19)}$, Kono ${ }^{(20)}$ and Mohondas et al. ${ }^{(21)}$, respectively. Protein concentrations were determined by the method of Lowry et ll $^{(22)}$, and the levels of reduced GSH were estimated by using the method of Ellman ${ }^{(23)}$. The estimation of lipid peroxidation in the liver was done by the method of Placer et $a l^{(24)}$. All these methods have been described briefly in our previous report ${ }^{(15)}$

\section{Hepatic zinc estimation}

$\mathrm{Zn}$ concentrations in liver samples were measured as described earlier ${ }^{(15)}$ using atomic absorption spectrophotometry (AA 800; Perkin-Elmer, Shelton, CT, USA).

\section{Data presentation and statistical analysis}

Data are presented as means and standard deviations. The experimental parameters from the OS treatment group (GII) and without OS exposure groups (GIII) were initially compared with the normal control (GI) using one-way ANOVA. The effect of NA supplementation and OS exposure in the treatment groups (GII and GIII) was then assessed using two-way ANOVA. Student's unpaired $t$ test was used to further analyse differences between group pairs (i.e. NAsupplemented groups and OS exposure groups). To compare the effect of OS treatment, the subgroups from GII were compared with the respective subgroups from GIII, for example GIIa with GIIIa. For comparison of NA supplementation within the GII and GIII groups, the NA-deficient groups (GIIa and GIIIa) were compared with the respective NA normal and NA excess groups.

\section{Results}

Body weight and food intake records for the OS pre-exposure experiment showed no significant difference in the different treatment groups and their subgroups. GII animals with OS treatment showed a slight decrease (NS) in weights and intake, indicating that OS pre-exposure along with $\mathrm{Zn}$ deficiency and dietary NA variation was tolerated by the animals. 
Effect on aspartate aminotransferase and alanine aminotransferase

The consequences of NA variation in the diet under $\mathrm{Zn}$ deficiency and OS pre-exposure on plasma AST and ALT levels are shown in Fig. 3. OS pre-exposure to the rats caused significant elevations in plasma ALT and AST levels in GII animals compared with the normal control group (GI). The highest AST and ALT levels were observed in GIIa $(P<0.001 v$. GI) animals, indicating increased hepatotoxicity due to tert-butyl hydroperoxide coupled with $\mathrm{Zn}$ and NA deficiency. Enzyme activities were reduced $(P<0.01)$ in GIIb and GIIc animals as the dietary NA level changed from the deficient to normal to excess states, respectively. Compared with GI animals, these enzymes were slightly elevated in GIIIa $(P<0.05)$ animals, indicating that even without OS treatment, the Zn-deficient diet affects the levels of liver marker enzymes. Moreover, in GIIIc animals, the Zn-deficient but NA excess diet showed comparable activities with GI animals.

OS post-exposure to the rats resulted in elevated levels of AST (145.39 (SD 8.1) IU/1) and ALT (113.8101 (SD 5.7) IU/1) in GIId animals, which remained towards the higher side even after excess NA supplementation in GIIf (AST: 116.4 (SD 2.5) IU/1; ALT: 71.295 (SD 3.9) IU/l) animals.

\section{Histopathological observations}

The effect of different treatments, i.e. OS pre- and postexposure with dietary NA variations, on liver morphology of selected groups is shown in Fig. 4. Liver from control rats (GI) showed preserved hepatic architecture with normal hepatocytes (Fig. 4(e)). In the rat liver from OS pre-exposure with the NA-deficiency group, it was observed that the hepatocytes showed necrosis with cytoplasmic vacuolisation. A dilated central vein was also observed in this sample (Fig. 4(a)). However, these effects were almost diminished by excess
NA supplementation in OS pre-exposure, since nearly preserved hepatic architecture with normal hepatocytes was observed (Fig. 4(b)). Maximum tissue destruction was evident in OS post-exposure with NA deficiency (Fig. 4(c)). Peritoneal fibrosis with a mononuclear cell inflammatory infiltrate was observed in the liver sample. With enhanced NA supplementation, tissue morphology was somewhat recovered, as a few focal areas of the vacuolar degeneration of hepatocytes with some dilated blood vessels were manifested (Fig. 4(d)).

\section{Effect of dietary nicotinic acid levels on the hepatic} antioxidant enzymes, glutathione, lipid peroxidation and zinc content

The results of OS pre- and post-exposure along with dietary NA levels on the hepatic primary antioxidant enzymes, lipid peroxidation, Zn and GSH levels are summarised in Tables 1 and 2 , respectively.

Comparison of group II and group III with normal control group I for the oxidative stress pre-exposure subgroups. OS pre-exposure to GIIa (with Zn-deficient and NA-deficient) animals resulted in significant $(P<0.001)$ depletion in SOD, catalase, GPx, GSH, Zn levels and elevated lipid peroxidation compared with normal control GI. The effect was less pronounced in GIIb and GIIC animals with normal and excess NA supplementation. Without OS treatment, the GIIIb and GIIIC groups showed a non-significant difference in the levels of all parameters compared with the GI group. However, the $\mathrm{Zn}$ and NA deficiency combination without OS in the GIIIa subgroup caused a decrease in GSH $(P<0.001), \mathrm{Zn}(P<0.01)$, SOD $(P<0.05)$ and GPx $(P<0.05)$ and an increase in lipid peroxidation $(P<0.05)$ levels.

Comparison of oxidative stress treatment between group II and group III animals for the oxidative stress pre-exposure subgroups. OS pre-exposure along with $\mathrm{Zn}$ and NA deficiency further worsened the antioxidant status in GIIa as

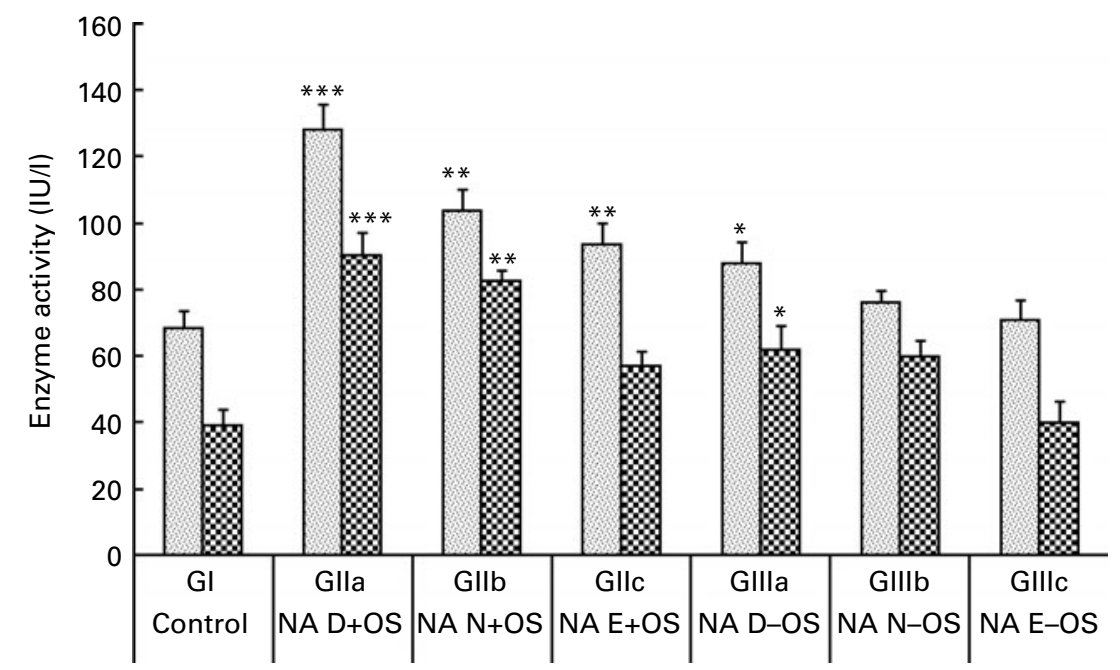

Fig. 3. Effect of dietary nicotinic acid (NA) variation on plasma enzymes aspartate aminotransferase ( $\square$ ) and alanine aminotransferase ( $\mathbb{Q}$ ) in animals treated with pre-exposure to oxidative stress (OS) conditions. Values are means, with standard deviations represented by vertical bars. NA D, NA deficient; NA N, NA normal; NA E, NA excess; GI, group I; GII, group II; GIII, group III. Mean value was significantly different from that of the normal control group (GI): ${ }^{\star} P<0.05,{ }^{\star \star} P<0.01$, ${ }^{\star \star \star} P<0.001$. 

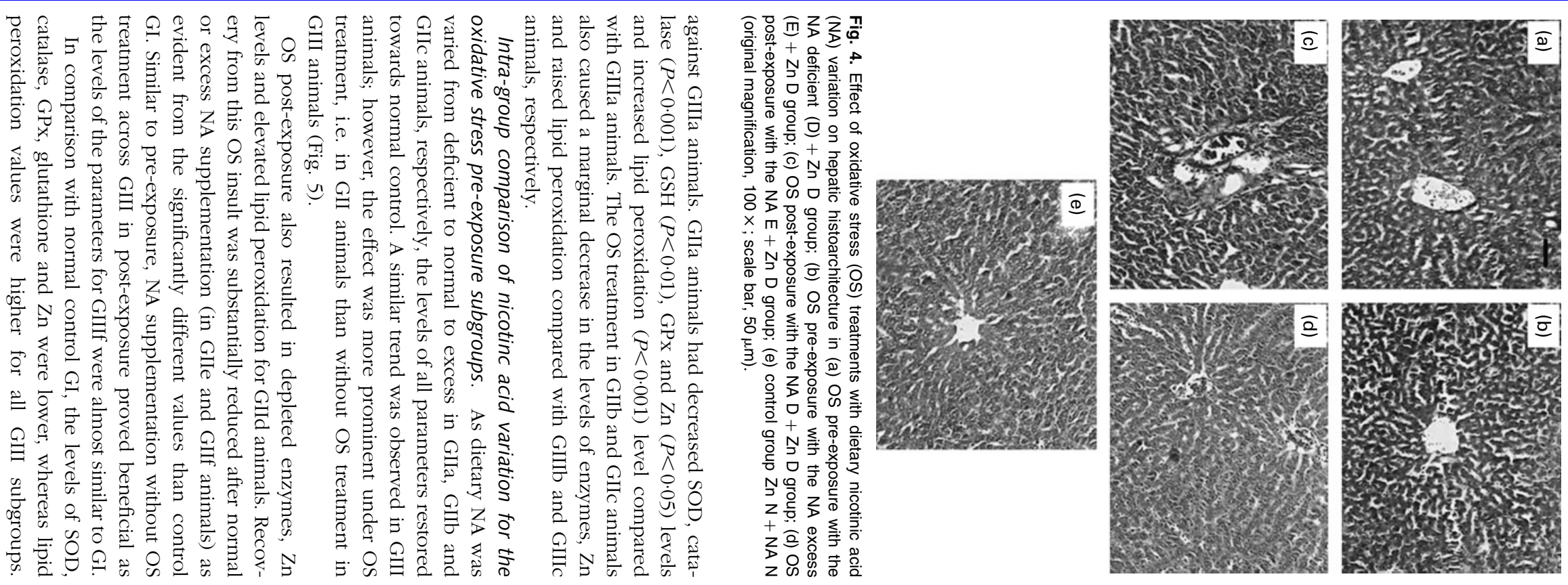

Table 1. Effect of dietary nicotinic acid (NA) variations on the hepatic antioxidant enzymes, glutathione (GSH), lipid peroxidation and zinc content in rats subjected to oxidative stress (OS) preexposure

(Mean values and standard deviations, $n 8$ )

\begin{tabular}{|c|c|c|c|c|c|c|c|c|c|c|c|c|}
\hline \multirow[b]{2}{*}{ Group } & \multicolumn{2}{|c|}{$\begin{array}{l}\text { SOD } \\
(\mathrm{U} / \mathrm{mg})^{9}\end{array}$} & \multicolumn{2}{|c|}{$\begin{array}{c}\text { Catalase }\left(\mu \mathrm{mol} \mathrm{H}_{2} \mathrm{O}_{2}\right. \\
\text { decomposed } / \mathrm{min} \\
\text { per mg protein) }\end{array}$} & \multicolumn{2}{|c|}{$\begin{array}{l}\text { GPx (nmol NADPH } \\
\text { reduced/min per mg } \\
\text { protein) }\end{array}$} & \multicolumn{2}{|c|}{$\begin{array}{l}\text { Lipid peroxidation } \\
\text { (nmol MDA/mg } \\
\text { protein) }\end{array}$} & \multicolumn{2}{|c|}{$\begin{array}{c}\text { GSH } \\
\text { (nmol/mg } \\
\text { protein) }\end{array}$} & \multicolumn{2}{|c|}{$\begin{array}{c}\mathrm{Zn} \\
\text { ( } \mu \mathrm{g} / \mathrm{g} \text { liver) }\end{array}$} \\
\hline & Mean & SD & Mean & SD & Mean & SD & Mean & SD & Mean & SD & Mean & SD \\
\hline GI (normal control) & 5.95 & 1.47 & 49.84 & 4.52 & 150.07 & 8.25 & 4.88 & 0.59 & $26 \cdot 12$ & 1.86 & $42 \cdot 38$ & 4.18 \\
\hline Glla (NA D + OS) & 3.05 ${ }^{* * *}+\dagger \dagger$ & 0.65 & $41 \cdot 27^{\star \star *}+\dagger \dagger$ & 3.62 & $130.94^{\star * *} \dagger$ & 8.71 & $7 \cdot 26^{\star * *}+\dagger \dagger$ & 0.34 & $20 \cdot 15^{\star \star *}+\dagger$ & $1 \cdot 11$ & $35 \cdot 07^{\star \star \star} \dagger$ & $2 \cdot 23$ \\
\hline Gllb (NA N + OS) & $3.94^{\star \star \star} \ddagger \ddagger$ & 0.67 & $44 \cdot 21^{\star \star}+\dagger$ & 3.23 & $138 \cdot 35^{\star \star}$ & 9.68 & $6.08^{\star \star \star} † \ddagger$ & 0.46 & $22 \cdot 41^{\star *} † \ddagger$ & 1.98 & $36 \cdot 54^{\star \star \star} \dagger$ & 3.23 \\
\hline Gllc (NA E + OS) & $4 \cdot 58^{\star} \neq \neq \ddagger$ & 1.04 & 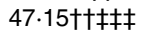 & 3.12 & 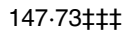 & $7 \cdot 35$ & $5 \cdot 75^{\star}+\neq \ddagger$ & 0.37 & $23 \cdot 20^{*} \ddagger \neq \ddagger$ & $2 \cdot 76$ & 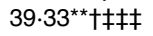 & 2.97 \\
\hline Gllla (NA D - OS) & $4 \cdot 68^{*}$ & 1.01 & $48 \cdot 15$ & 3.01 & $141.66^{*}$ & $9 \cdot 29$ & $5 \cdot 78^{*}$ & 0.23 & $21 \cdot 48^{\star \star \star}$ & 1.95 & $38 \cdot 72^{\star \star}$ & 3.71 \\
\hline Glllb (NA N - OS) & $4.72^{\star}$ & $1 \cdot 12$ & 50.03 & 4.86 & 143.65 & 8.97 & $5.53 \neq \ddagger$ & $0 \cdot 13$ & $23 \cdot 41^{*}$ & $2 \cdot 56$ & 40.79 & 3.70 \\
\hline Glllc (NA E - OS) & $5 \cdot 13$ & 1.01 & $51 \cdot 17$ & 2.51 & $148 \cdot 16$ & 9.82 & $5 \cdot 16 \neq \pm \ddagger$ & 0.29 & $25 \cdot 24 \ddagger$ & $2 \cdot 94$ & $41 \cdot 31$ & 2.35 \\
\hline Effect of OSף १ & \multirow{2}{*}{\multicolumn{2}{|c|}{$\begin{array}{l}3.74 \S \\
2.29 \text { (NS) }\end{array}$}} & \multicolumn{2}{|l|}{$15.44 \|$} & \multicolumn{2}{|c|}{0.87 (NS) } & \multicolumn{2}{|c|}{$27 \cdot 41 \|$} & \multicolumn{2}{|c|}{2.71 (NS) } & \multicolumn{2}{|l|}{$10 \cdot 55 \|$} \\
\hline Effect of NAף १ & \multirow{2}{*}{\multicolumn{2}{|c|}{$\begin{array}{l}2.29 \text { (NS) } \\
0.11 \text { (NS) }\end{array}$}} & \multirow{2}{*}{\multicolumn{2}{|c|}{$\begin{array}{l}2.65 \text { (NS) } \\
0.51 \text { (NS) }\end{array}$}} & \multirow{2}{*}{\multicolumn{2}{|c|}{$\begin{array}{l}4.59 \S \\
0.53 \text { (NS) }\end{array}$}} & \multirow{2}{*}{\multicolumn{2}{|c|}{$\begin{array}{l}6.39 \S \\
0.44 \text { (NS) }\end{array}$}} & \multicolumn{2}{|c|}{2.04 (NS) } & \multirow{2}{*}{\multicolumn{2}{|c|}{$\begin{array}{l}2.97 \text { (NS) } \\
1.41 \text { (NS) }\end{array}$}} \\
\hline Interaction between NA and OS $\uparrow$ & & & & & & & & & 0.32 & & & \\
\hline
\end{tabular}

SOD, superoxide dismutase; GPx, glutathione peroxidase; MDA, malondialdehyde; Gl, group I; GII, group II; GIII, group III; D, deficient; N, normal; E, excess.

Mean values of all subgroups were significantly different from those of normal control GI: ${ }^{*} P<0.05,{ }^{* *} P<0.01,{ }^{* \star *} P<0.001$.

Mean values of Glla-Gllc subgroups were significantly different from those of the Gllla-GIllc subgroups (for OS treatment): $\uparrow P<0.05, \dagger \dagger P<0.01,+\dagger \dagger P<0.001$

Mean values of the Gllb-Glllc and Glllb-Glllc subgroups were significantly different from those of the Glla and Gllla subgroups (for NA variation): $\ddagger P<0.05$, $\ddagger \ddagger P<0.01, \ddagger \ddagger \ddagger P<0.01$.

$\S P<0.05$.

I One unit $(\mathrm{U})$ of enzyme is inverse of the amount of protein required to inhibit the reduction rate of nitroblue tetrazolium by $50 \%$.

१ ๆ Results of two-way ANOVA, as indicated by the $F$ value. 

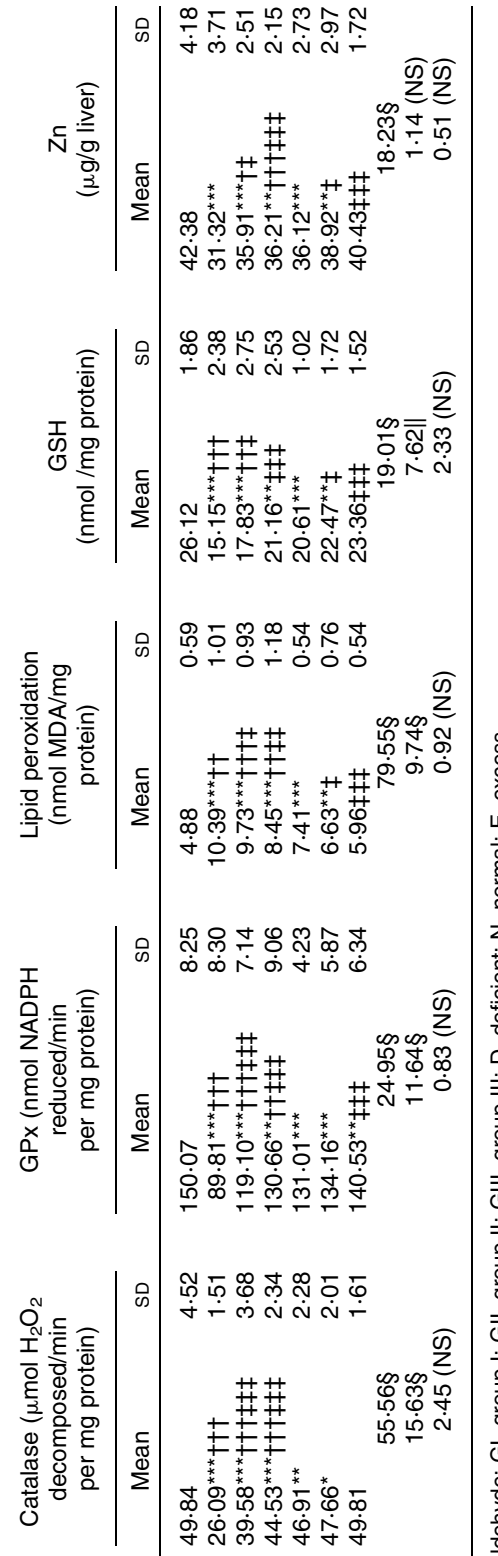

The reason may be the $\mathrm{Zn}$-deficient diet given to these groups. Second, the antioxidant status of GIII from the pre-exposure experiment was better than that from the post-exposure experiment.

\section{Discussion}

The increased AST and ALT levels in GIIa and GIId animals with OS treatment and $\mathrm{Zn}$ deficiency indicated significant liver damage, which is in agreement with earlier reports ${ }^{(25,26)}$. The restoration of AST and ALT levels due to normal and excess NA levels suggests its possible role in the recovery of normal liver function under $\mathrm{Zn}$ deficiency and OS. This may be directly due to improved $\mathrm{Zn}$ uptake as observed in an in vitro study ${ }^{(11)}$. Liver histopathological observations, where the least damage was observed in rats with OS pre-exposure and fed with an excess NA diet afterwards, also support the beneficial role of NA in OS pre-exposure condition. However, NA supplementation before OS post-exposure did not ensure the total prevention of oxidative damage.

The present study indicated a decrease in the activity of SOD in GIIa and GIIIa animals. Several studies have shown that $\mathrm{Zn}$ deficiency leads to a significant decrease in SOD activity in various tissues ${ }^{(27-29)}$. However, NA supplementation in GIIc animals significantly improved the levels of $\mathrm{Zn}$, and in turn, SOD activity, which could be attributed to the antioxidant property of NA and $\mathrm{Zn}$.

Results indicated a significant decrease in the activities of GPx and catalase in GIIa rats. These lower levels in GIIIa animals may be due to the $\mathrm{Zn}$ - and NA-deficient diet, as both $\mathrm{Zn}$ deficiency $^{(30)}$ and NA deficiency ${ }^{(31)}$ lead to the generation of OS. These activities were improved with increasing NA supplementation in the diet. NA supplementation alone ${ }^{(32)}$ or in combination with other factors ${ }^{(33,34)}$ has been shown to mitigate the up-regulation of oxidative and inflammatory systems with a decrease in NO, lipid peroxides and an increase in GSH and SOD levels.

In the present study, a significant increase in the lipid peroxidation level was observed in OS-treated and NA-deficient rats (GIIa), and supplementation of NA (GIIb and GIIc) resulted in a decrease in malondialdehyde levels. This may be due to increased hepatic $\mathrm{Zn}$ contents. The result seems to support the previous findings ${ }^{(25,35,36)}$, wherein it has been suggested that rats fed on a $\mathrm{Zn}$-deficient diet are more susceptible to peroxidative tissue damage. Also, the observed increase in lipid peroxidation was concurrent with a remarkable decrease in GSH levels in OS-treated rats as well as in non-OS-treated groups. Younes \& Siegers ${ }^{(37)}$ have also observed that depletion of GSH enhances lipid peroxidation. GSH is a central constituent of antioxidant defence and acts as an essential cofactor for antioxidant enzymes such as $\mathrm{GPx}^{(38)}$. Under OS, GSH is consumed by GSH-related enzymes to detoxify peroxides in the water phase ${ }^{(39)}$. Recently, Cortese et al. $^{(40)}$ demonstrated that $\mathrm{Zn}$ protects endothelial cells from $\mathrm{H}_{2} \mathrm{O}_{2}$-induced $\mathrm{OS}$ by increasing GSH biosynthesis. In the present study, the observed marked elevation in lipid peroxidation and depletion in GSH activity in GIIa animals suggests that depleted GSH stores may partly result in 
(a)

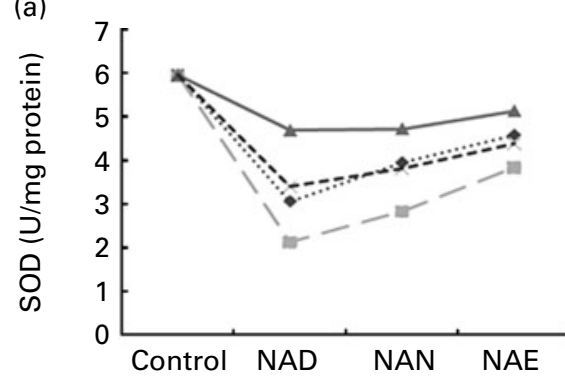

(c)
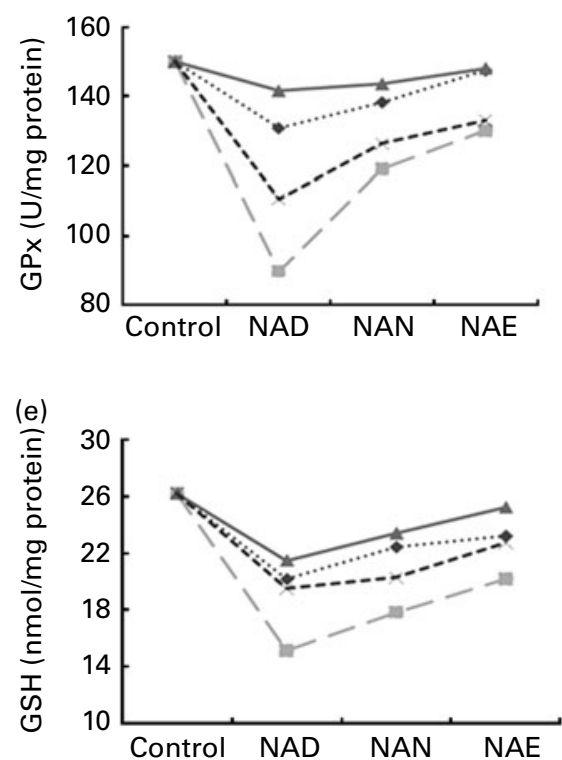

(b)

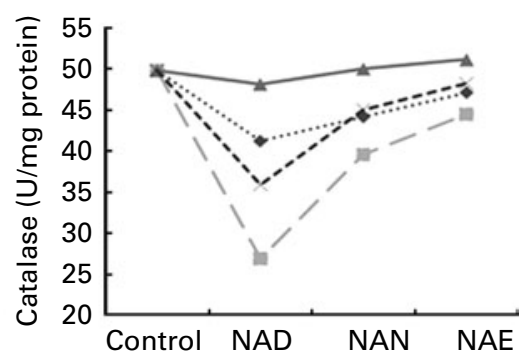

(d)

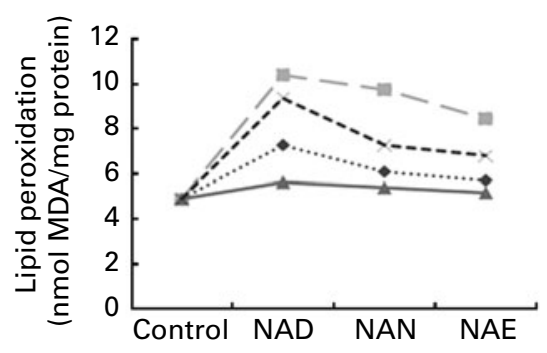

(f)

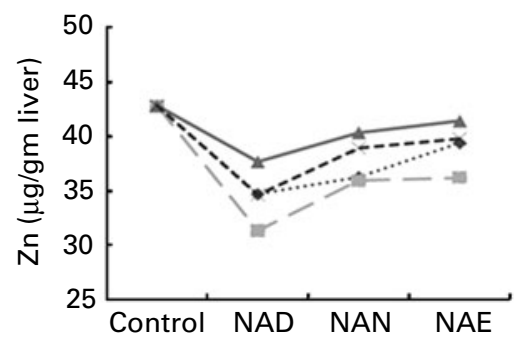

Fig. 5. Effect of dietary nicotinic acid (NA) variations (NA deficient (D), NA normal (N) and NA excess (E)) on the hepatic antioxidant enzymes ((a) superoxide dismutase (SOD), (b) catalase and (c) glutathione peroxidase (GPx)), (d) lipid peroxidation, (e) glutathione and (f) Zn contents in rats subjected to treatments. (a) OS pre-exposure groups Glla, Gllb and Gllc (............); (b) OS post-exposure groups Glld, Glle and Gllf (---); (c) without OS pre-exposure groups Gllla,

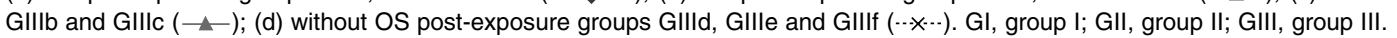

increased peroxidation, which are otherwise capable of moderating the amount of lipid peroxidation. However, NA supplementation to OS-treated Zn-deficient GIIb and GIIc rats significantly increased the levels of GSH compared with GIIa animals. NADPH is an essential coenzyme of the GSH reductase, which is involved in the reduction of oxidised to reduced GSH. Treatment with excess NA in GIIc showed near-normal levels of GSH, which may be conceived as the effect of enhanced tissue $\mathrm{Zn}$ levels by NA, reduction in hepatic peroxidative damage followed by a respite in GPx activity, thereby leading to restoration of the GSH content. In GIII animals, GSH levels improved accordingly with increased dietary NA contents.

It is well known that the liver performs an important function in the short-term regulation of trace-element metabolism $^{(41)}$. Through its myriad biological functions, $\mathrm{Zn}$ plays an important role in the therapy of several liver diseases and has been shown to attenuate or protect against a variety of hepatotoxins such as carbon tetrachloride, bromobenzene and several metals ${ }^{(42-44)}$. The OS pre-exposure study indicated a significant depression of hepatic $\mathrm{Zn}$ content after $\mathrm{Zn}$ deficiency and OS treatment. However, NA treatment from
GIIa to GIIc rats raised the hepatic $\mathrm{Zn}$ levels compared with the reference levels of GI rats. Interestingly, administration of NA to Zn-deficient GIII rats without OS treatment had not improved the hepatic $\mathrm{Zn}$ content to that extent, indicating the specific role of OS for its interaction with NA and Zn. Thus, in OS pre-exposure, it was found that NA enhanced the hepatic Zn level, which in turn might have resulted in hepatoprotection against OS-induced damage.

The interaction between $\mathrm{Zn}$ and NA is bidirectional as supplementation of any one improves the metabolism of the other. Vannucchi et $a l .{ }^{(45)}$ had reported that in NA-deficient rats, $\mathrm{Zn}$ repletion caused activation of NA metabolism. Similar results were obtained in another study from our laboratory ${ }^{(15)}$

Exogenously added NA has been shown to markedly increase NAD levels in mammalian tissues including liver, kidney and heart ${ }^{(17)}$ and concomitantly resulting in the reversal of OS-induced cell injury in kidney epithelial HEK 293 cells ${ }^{(3)}$. Maiese et $a l .{ }^{(2)}$ had reviewed the role of nicotinamide as an antioxidant and different unique cellular pathways involving nicotinamide that determine cellular longevity, cell survival and unwanted cancer progression. In vitro $\mathrm{Zn}$ uptake by human erythrocytes has been studied using blood samples 
of ten healthy subjects. It has been found that $8 \mathrm{~mm}-\mathrm{NA}$ or NADPH increased ${ }^{65} \mathrm{Zn}$ uptake by 38.9 and $43.1 \%$ in the fasting, and by 70.9 and $28.1 \%$ in postprandial conditions ${ }^{(14)}$. When mice were fed with NA-deficient, -adequate and -excess synthetic diets for 4 weeks, it has been observed that, in comparison with the NA-deficient diet, percentage of $\mathrm{Zn}$ absorption, intestinal $\mathrm{Zn}$, percentage of $\mathrm{Hb}$ and hepatic Fe increased significantly under NA-adequate and -excess conditions $^{(14)}$. The present study imparts another dimension to the antioxidant role of NA through the improvement in hepatic $\mathrm{Zn}$ uptake.

The results of all parameters signify that NA supplementation is more beneficial under the pre-exposure condition, as it assures more favourable circumstances to combat oxidative injury by enhancing $\mathrm{Zn}$ uptake under Zn deficiency. Hence, NA supplementation can be a better treatment strategy rather than prophylaxis.

In conclusion, dietary NA supplementation improves $\mathrm{Zn}$ uptake, acts as an antioxidant along with $\mathrm{Zn}$ and results in hepatoprotection against OS-induced damage in rats. The results collectively suggest that NA supplementation may have a therapeutic potential in the treatment of $\mathrm{Zn}$ deficiency-related complications and oxidative liver damage.

\section{Acknowledgements}

R. S. T. thanks the University Grants Commission, India, for a Senior Research Fellowship. All authors declare that they have no commercial/financial conflict of interest. R. S. T. and S. G. T. were involved in the study design, data collection, data analysis, data interpretation, literature search and manuscript preparation. V. V. A. was involved in the study design, data analysis, data interpretation, literature search, manuscript preparation and review of the manuscript.

\section{References}

1. Ratnam DV, Ankola DD, Bhardwaj V, et al. (2006) Role of antioxidants in prophylaxis and therapy: a pharmaceutical perspective. J Control Release 113, 189-207.

2. Maiese K, Chong ZZ, Hou J, et al. (2009) The vitamin nicotinamide: translating nutrition into clinical care. Molecules 14, 3446-3485.

3. Hara N, Yamada K, Shibata T, et al. (2007) Elevation of cellular NAD levels by nicotinic acid and involvement of nicotinic acid phosphoribosyl transferase in human cells. $J$ Biol Chem 282, 24574-24582.

4. Prasad AS, Bao B, Beck FWJ, et al. (2004) Antioxidant effect of zinc in humans. Free Radic Biol Med 37, 1182-1190.

5. Powell SR (2000) The antioxidant properties of zinc. J Nutr 130, 1447S-1454S.

6. Andrews GK (2001) Cellular zinc sensors: MTF-1 regulation of gene expression. Biometals 14, 223-237.

7. Stamoulis I, Kouraklis G \& Theocharis S (2007) Zinc and the liver: an active interaction. Dig Dis Sci 52, 1595-1612.

8. Grungreiff K (2002) Zinc in liver disease. J Trace Elem Exp Med 15, 67-78.

9. Oteiza PI, Clegg MS, Zago MP, et al. (2000) Zinc deficiency induces oxidative stress and AP-1 activation in $3 \mathrm{~T} 3$ cells. Free Radic Biol Med 28, 1091-1099.
10. Ho E \& Ames BN (2002) Low intracellular zinc induces oxidative DNA damage, disrupts p53, NF kappa B, and AP1 DNA binding, and affects DNA repair in a rat glioma cell line. Proc Natl Acad Sci U S A 99, 16770-16775.

11. Agte VV, Nagmote RV \& Chiplonkar SA (2004) Role of vitamin-zinc interactions on in vitro zinc uptake by human erythrocytes. Biol Trace Elem Res 99, 99-112.

12. Tupe RS \& Agte VV (2010) Interactions of water soluble vitamins in Zn transport of Caco-2 cells and their implications under oxidative stress conditions. Eur J Nutr 49, 53-61.

13. Tupe RS, Chiplonkar SA \& Agte VV (2007) Changes in zinc uptake in response to ascorbic acid and folic acid in rat liver slices under normal and oxidative stress conditions. Biofactors 30, 27-34.

14. Agte VV, Paknikar KM \& Chiplonkar SA (1997) Effect of nicotinic acid on zinc and iron metabolism. Biometals 10, 271-276.

15. Tupe RS, Tupe SG, Tarwadi KV, et al. (2010) Effect of different dietary zinc levels on hepatic antioxidant and micronutrients indices under oxidative stress conditions. Metabolism 59, 1603-1611.

16. Reeves PG, Nielsen FH \& Fahey (1993) GCAIN-93 purified diets for laboratory rodents: final report of the American Institute of Nutrition ad hoc writing committee on the reformulation of the AIN-76A rodent diet. J Nutr 123, 1939-1951.

17. Jackson TM, Rawling JM, Roebuck BD, et al. (1995) Large supplements of nicotinic acid and nicotinamide increase tissue $\mathrm{NAD}^{+}$and poly(ADP-ribose) levels but do not affect diethylnitrosamine-induced altered hepatic foci in Fischer344 rats. $J$ Nutr 125, 1455-1461.

18. Boyonoski AC, Spronck JC, Jacobs RM, et al. (2002) Pharmacological intakes of niacin increase bone marrow poly(ADP-ribose) and the latency of ethylnitrosoureainduced carcinogenesis in rats. J Nutr 132, 115-120.

19. Clairborne A \& Fridovich I (1979) Purification of the o-dianisidine peroxidase from Escherichia coli B. Physicochemical characterization and analysis of its dual catalatic and peroxidatic activities. J Biol Chem 254, 4245-4252.

20. Kono Y (1978) Generation of superoxide radical during autoxidation of hydroxylamine and an assay for superoxide dismutase. Arch Biochem Biophys 186, 189-195.

21. Mohandas J, Marshell JJ, Duggin GG, et al. (1984) Differential distribution of glutathione and glutathione related enzymes in rabbit kidney: possible implications in analgesic neuropathy. Cancer Res 44, 5086-5091.

22. Lowry OH, Rosebrough NJ, Farr AL, et al. (1951) Protein measurement with the Folin phenol reagent. $J$ Biol Chem 193, 265-275.

23. Ellman GC (1959) Tissue sulfhydryl groups. Arch Biochem Biophys 82, 70-77.

24. Placer ZA, Crushman LL \& Johnson BC (1966) Estimation of products of lipid peroxidation (MDA) in biochemical systems. Anal Chem 16, 359-364.

25. Parsons SE \& Disilvestro RA (1994) Effects of mild zinc deficiency, plus or minus an acute-phase response, on galactosamine-induced hepatitis in rats. Br J Nutr 12, 611-618.

26. Ishikawa Y, Kudo H, Suzuki S, et al. (2008) Down regulation by a low-zinc diet in gene expression of rat prostatic thymidylate synthase and thymidine kinase. Nutr Metab 5, 12.

27. Cao G \& Chen J (1991) Effects of dietary zinc on free radical generation, lipid peroxidation, and superoxide dismutase in trained mice. Arch Biochem Biophys 291, 147-153.

28. Shaheen AA \& el-Fattah A (1995) Effect of dietary zinc on lipid peroxidation, glutathione, protein thiols levels and superoxide dismutase activity in rat tissues. Int $\mathrm{J}$ Biochem Cell Biol 27, 89-95. 
29. Olin KL, Golup MS, Gershwin ME, et al. (1995) Extracellular superoxide dismutase activity is affected by dietary zinc intake in nonhuman primate and rodent models. Am J Clin Nutr 61, 1263-1267.

30. Oteiza PI, Clegg MS, Zago MP, et al. (2000) Zinc deficiency induces oxidative stress and AP-1 activation in $3 \mathrm{~T} 3$ cells. Free Radic Biol Med 28, 1091-1099.

31. Tang K, Sham H, Hui E, et al. (2008) Niacin deficiency causes oxidative stress in rat bone marrow cells but not through decreased NADPH or glutathione status. J Nutr Biochem 19, 746-753.

32. Cho KH, Kim HJ, Rodriguez-Iturbe B, et al. (2009) Niacin ameliorates oxidative stress, inflammation, proteinuria, and hypertension in rats with chronic renal failure. Am J Physiol Renal Physiol 297, F106-F113.

33. Perumala SS, Shanthib P \& Sachdanandama P (2005) Augmented efficacy of tamoxifen in rat breast tumorigenesis when gavaged along with riboflavin, niacin, and CoQ10: effects on lipid peroxidation and antioxidants in mitochondria. Chem Biol Interact 152, 49-58.

34. Salama RH, Nassar AY, Nafady AA, et al. (2007) A novel therapeutic drug (copper nicotinic acid complex) for nonalcoholic fatty liver. Liver Int 27, 454-464.

35. Oteiza PI, Olin KL, Fraga CG, et al. (1995) Zinc deficiency causes oxidative damage to proteins, lipids and DNA in rat testes. J Nutr 125, 823-829.

36. Kraus A, Roth HP \& Kirchgessner M (1997) Supplementation with vitamin $\mathrm{C}$, vitamin $\mathrm{E}$ or beta carotene influences osmotic fragility and oxidative damage of erythrocytes of zinc-deficient rats. J Nutr 127, 1290-1296.
37. Younes M \& Siegers CP (1981) Mechanistic aspects of enhanced lipid peroxidation following glutathione depletion in vivo. Chem Biol Interact 34, 257-266.

38. Kidd PM (1997) Glutathione: systemic protectant against oxidative and free radical damage. Alt Med Rev 2, 155-176.

39. Cathcart RF III (1985) Vitamin C: the nontoxic, nonratelimited, antioxidant free radical scavanger. Med Hypotheses 18, 67-74.

40. Cortese MM, Suschek CV, Wetzel W, et al. (2008) Zinc protects endothelial cells from hydrogen peroxide via Nrf2dependent stimulation of glutathione biosynthesis. Free Radic Biol Med 44, 2002-2012.

41. Failla ML \& Kiser RA (1983) Hepatic and renal metabolism of copper and zinc in the diabetic rat. Am J Physiol 244, $113-121$.

42. Liu J, Kershaw WC \& Klaassen CD (1992) Protective effects of zinc on cultured rat primary hepatocytes to metals with low affinity for metallothionein. J Toxicol Environ Health 35, 51-62.

43. DiSilvestro RA \& Carlson GP (1994) Effects of mild zinc deficiency, plus or minus acute phase response, on $\mathrm{CCl}_{4}$ hepatotoxicity. Free Radic Biol Med 16, 57-61.

44. Afonne OJ, Orisakwe OE, Ndubuka GI, et al. (2000) Zinc protection of mercury induced hepatic toxicity in mice. Biol Pharm Bull 23, 305-308.

45. Vannucchi H, Kutnink M \& Sauberlich H (1986) Interaction among niacin, vitamin $\mathrm{B}_{6}$ and zinc in rats receiving ethanol. Int J Vit Nutr Res 56, 355-362. 